\title{
Secondary Metabolites Phytochemical Analysis of n- Hexane, Ethyl Acetate and Ethanol Extracts of Sarang Banua (Clerodendrum fragrans Vent Willd) Leaves
}

\author{
Murniaty Simorangkir ${ }^{1}$, Bajoka Nainggolan ${ }^{2}$, Saronom Silaban $^{3}$ \\ \{murniatysimorangkir@unimed.ac.id\} \\ Department of Chemistry, Universitas Negeri Medan, Medan ${ }^{1,2,3}$
}

\begin{abstract}
Sarang banua plant (Clerodendrum fragransVent Willd), the Verbanaceae family is found in village Raya Usang,Simalungun district of Indonesia, traditionally used as medicinal plant. Secondary metabolite research from C. fragrans local plant extract aims to develop its potential as a drug ingredient. The result of phytochemical analysis showed that in the $n$-hexane extract of $\mathrm{C}$. fragrans leaf there are secondary metabolites alkaloid, steroid and flavonoid. In the ethyl acetate extract there are alkaloids, steroids, saponins and tannins. In ethanol extracts there are alkaloids, triterpenoids, flavonoids, saponins, tannins and quinones. The yield of n-hexane extract, ethyl acetate and ethanol of C. fragransVent Wiild were $3.82 \% ; 10.63 \%$ and $15.42 \%(\mathrm{ww})$.
\end{abstract}

Keywords: Phytochemicals, Leaves, Sarangbanua plant (Clerodendrum fragransVent Willd), Medicinal plant of Indonesian.

\section{Introduction}

Sarang banua plant is commonly found in Simalungun, Indonesia. Sarang banua have been used by the community as a traditional (ethnomedical) medicinal plant,including medication for stomach pain, fever, high blood pressure, sugar medicine, cough and others. Sarang banua plantt (Clerodendrum fragrans) are shrubs, grow to around $2.5-3 \mathrm{~m}$. The leaves are simple and opposite, oval and wide, about $6-25 \mathrm{~cm}$ long and $5-25 \mathrm{~cm}$ wide. Flowers are whitish pink (whitish pink) and flower petals are usually reddish purple, flowers are 10-15 mm long (Figure 1). Based on the results of the determination of plants by the "Herbarium Bogoriense" Botanical Field of the Biology Research Center-LIPI Bogor, sarang banua plant is a type of Clerodendrum fragrans Vent Willd, including the Verbanaceae family and has been stored in herbarium form "Herbarium Bogoriense" since June 2017.

The Genus Clerodendrum (Family of Verbanaceae) has more than five hundred species that have been identified, which are semi-woody shrubs and are widespread in the tropics. Root, stem, leaf extracts of several species of the genus Clerodendrum have been traditionally used for the treatment of asthma, cataracts, malaria, blood, skin and lung diseases (Shrivastava and Patel, 2007).

According to Kar, et al., (2014) different plant parts such as leaves and extract of C. indicum, C.pholmidis, C.serratum, C.trichotomum, C. chinense and C. petasites extracts have been used for the treatment of rheumatism, asthma, febrifuge, incephalagia, ophthalmia and other inflammatory diseases. Types of plants C. indicum and C. inerme are used for the 
treatment of cough, genital infections, skin diseases, elephantiasis, rheumatism, burns, vermifuge, febrifuge, malaria and so on. C.pholmidis, C. colebrookianum, C. calamitosum and C. trichotomum plants have been used as anti-diabetic, anti-hypertensive andsedative. Ethanol extract of Clerodendrum infortunatum leaves showed effective anti-microbial activity against several Gram negative bacteria and fungal strains. Ethanol, hexane, chloroform and water extracts from the roots, leaves and stems of Clerodendrum viscosum showed effective antibacterial activity against strains of Gram-positive, Gram-negative bacteria and fungi.

Medicinal plants are pharmacological sources that are rich in active secondary metabolites such as alkaloids, steroids, tannins and phenol compounds, which are available at low cost and easily decomposed. Senjobi et al. (2017) reported that the Clerodendrum volubile plant could be used as an analgesic, containing chemical compounds saponins, tannins, anthraquinones, flavonoids, alkaloids, plhinoin, phenols, terpenes and glycosides.

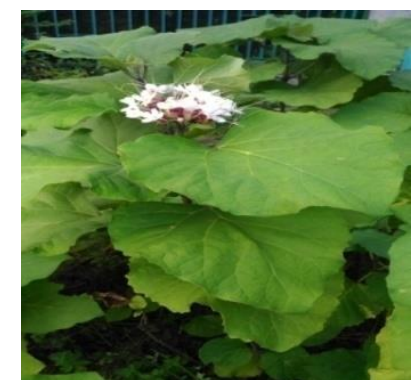

Fig.1. Sarang banua plant (Clerodendrum fragrans Vent Willd) from Simalungun Region, Indonesia.

Secondary metabolites in plants can be obtained through extraction using solvents in accordance with the principle of solubility and polarity of secondary metabolites. According to Smallwood (1996), n-hexane, ethyl acetate and ethanol solvents have different polarities, namely non-polar, semi-polar and polar with dielectric constant $\left(20^{\circ} \mathrm{C}\right)$, each of which is 1.90 ; 6.02 and 22.40.

Publication or research on sarang banua (C. fragrans Vent Willd) plant is still very limited. Phytochemical analysis of secondary metabolites from extracts of n-hexane, ethyl acetate and ethanol of sarang banua plant that are widely found in the Simalungun region of Indonesia needs to be done to develop the potential of local medicinal plants as raw materials for natural medicine. The development and research of this plant-based drug ingredient is very beneficial in addition to the fact that the source of natural ingredients is sufficiently available, also to overcome the side effects and the high price of synthetic drugs and antibiotics.

\section{Materials And Methods}

\subsection{Materials and Tools}

The tools used are vacuum rotary evaporator, Buchner funnel, vortex mixer and glass (pyrex) equipment, which are separating funnels, erlenmeyer flasks, measuring flasks, stirring rods, volume pipettes, test tubes and measuring cups.

The chemicals used are technical grade solvents for extraction including $\mathrm{n}$-hexane, ethyl acetate, ethanol and proanalyst (pa) (Merck) chemicals including chloroform, ether, amyl alcohol, glacial acetic acid, anhydrous acetic acid, sulfuric acid (p), ethanol 96\%, $\mathrm{NaOH}, \mathrm{HCl}$, 
$\mathrm{HNO}_{3}, \mathrm{Bi}(\mathrm{NO} 3)_{3}, \mathrm{HgCl}_{2}, \mathrm{KI}$. The plant material used is fresh leaves of sarang banua (C. fragrans Vent Willd), originating from Raya Usang village, Dolok Masagul sub-district, Simalungun district, North Sumatra, Indonesia. Plant sample was identified by the "Herbarium Bogoriense" in the Bogor LIPI-Biology Research Center.

Mayer Reagent: 1,360 g of $\mathrm{HgCl}$ were weighed, dissolved in distilled water up to $60 \mathrm{~mL}$. In another container as much as $5 \mathrm{~g}$ of $\mathrm{KI}$ is dissolved in $10 \mathrm{~mL}$ of distilled water. The two solutions are mixed and distilled water is added to a volume of $100 \mathrm{~mL}$ solution (Harborne, 1998).

Dragendorff Reagent: As much as $8.0 \mathrm{~g}$ of $\mathrm{KI}$ dissolved in $20 \mathrm{~mL}$ of distilled water (solution 1). A total of $0.86 \mathrm{~g}$ of bismuthnitrate was dissolved in $2 \mathrm{~mL}$ of distilled water (solution 2). Both solutions were mixed and added $7.0 \mathrm{~mL} \mathrm{HCl}(\mathrm{p})$ and diluted with distilled water to a volume of $100 \mathrm{~mL}$ solution (Harborne, 1998). Lieberman Burchard Reagent: A total of $5.0 \mathrm{~mL}$ of sulfuric acid (p) was put into a $50 \mathrm{~mL}$ solution of $96 \%$ ethanol, then $5.0 \mathrm{~mL}$ of anhydrous acetic acid was added (Harborne, 1998).

\section{2 Plant Extraction}

A total of $4.0 \mathrm{~kg}$ of fresh C. fragrans Vent Willd leaves were washed clean, drained, dried and protected from direct sunlight and mechanically ground to a simplicia powder (515.5 g). The simplicia powder of C. fragrans Vent Willd leaves was macerated with solvents with a polar level, namely n-hexane solvent, followed by ethyl acetate and ended with ethanol solvent.

Simplicia powder of C. fragrans Vent Willd leaves $(500.0 \mathrm{~g})$ were macerated with $\mathrm{n}$ hexane solvent, filtered and the filtrate obtained was concentrated on the rotary evaporator vacuum to obtain concentrated n-hexane extract. The pulp portion was macerated with ethyl acetate solvent, filtered and the filtrate obtained was concentrated to obtain concentrated ethyl acetate extract. Furthermore, the pulp portion was re-macerated with ethanol solvent, filtered and the filtrate obtained was concentrated to obtain concentrated ethanol extract. Each maceration process for each solvent lasts for 48 hours, with three times the addition of solvent. From the extraction results obtained each yield of n-hexane, ethyl acetate and concentrated ethanol extract from C. fragrans Vent Willd leaves.

\subsection{Phytochemical Test}

Phytochemical testing of secondary metabolites of C. fragrans Vent Willd leaf extract was carried out as follows:

\subsubsection{Identification of Alkaloid Groups}

A total of $0.50 \mathrm{~g}$ of extract plus $5 \mathrm{~mL}$ of $10 \%$ hydrochloric acid, whipped and added 5 $\mathrm{ml}$ of $10 \%$ ammonia solution. Extracted with $10 \mathrm{~mL}$ of chloroform and evaporated. The residual evaporation plus $1.5 \mathrm{~mL}$ of $2 \%$ hydrochloric acid, divided into two tubes. The first tube was added with 3 drops of Mayer reagent, the formation of a yellowish white precipitate showed the presence of alkaloids. The second tube is added with 4 drops of Dragendorff reagent, the formation of brick red deposits indicates the presence of alkaloids (Harborne, 1998). 


\subsubsection{Identification of Steroid and Triterpenoid}

A total of $0.5 \mathrm{~g}$ extract extracted with $10 \mathrm{~mL}$ ether. A total of $0.5 \mathrm{~mL}$ of the solution was tested with Lieberman Burchard reagent. The formation of blue or green indicates the presence of steroids and green or purple shows triterpenoid (Harborne, 1998).

\subsubsection{Identification of Flavonoids, Saponins, Tannins and Quinines}

A total of $0.50 \mathrm{~g}$ of the extract was dissolved in $10 \mathrm{~mL}$ of water and placed on a water bath, then the solution was divided into four tubes. To the first tube $100 \mathrm{mg}$ of magnesium powder is added and $1 \mathrm{~mL}$ of concentrated hydrochloric acid and $3 \mathrm{~mL}$ of amyl alcohol are added, shaken vigorously and allowed to separate, red, yellow, orange in the amyl alcohol layer indicating flavonoids. The second tube is shaken vertically for 10 seconds, it will form a stable foam, left for 10 minutes, added 1 drop of $1 \%$ hydrochloric acid. If the foam is not lost, it shows saponin. The third tube is added with a few drops of $1 \mathrm{~N}$ sodium hydroxide, the red filtrate shows quinone. The fourth tube is added with a few drops of $1 \%$ iron (III) chloride solution, the formation of dark blue or blackish green filtrate indicates the presence tannin (Harborne, 1998).

\section{Results And Discussion}

\subsection{Plant Extraction}

The selection of maceration method for extracting the leaves of C. fragrans Vent Willd in addition to its effectiveness, practicality, safety, and economics, also aims to avoid damage to the active compounds in the leaves of the banua nest which are not heat resistant. Maseration is done by soaking the C. fragrans Vent Willd leaf powder in a solvent for 48 hours, by adding the solvent three times, then releasing the solvent from the extract using a vacuum rotary evaporator. The selection of solvents in the maceration process is based on the principle of "like disolve like" solubility, meaning that polar compounds only dissolve in polar solvents, and vice versa for semipolar and non-polar compounds.

Solvents used in this study for maceration are non-polar solvents to polar solvents namely n-hexane, ethyl acetate and ethanol. The use of various types of solvents with different polarity levels was carried out to obtain extracts with optimal results from compounds of unknown type. The yield of n-hexane extract, ethyl acetate extract and ethanol extract of C. fragrans Vent Willd leaves were 3.82; 10.63; 15.42\% (w/w) (Figure 2). 


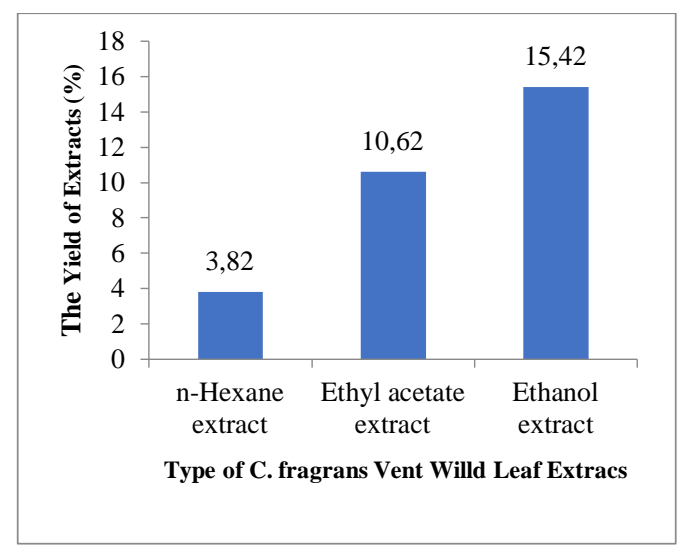

Fig. 2. The yield of extracts (\%) of C. fragrans Vent Willd leaf extract.

\subsection{Phytochemical Analysis}

Phytochemical analysis is one way to find out the secondary metabolites in a plant. Secondary metabolite compounds in plants include alkaloids, flavonoids, steroids and triterpenoids, tannins and others. Basically these secondary metabolites are toxic to plants and animals. In some plants the secondary metabolites produced are used to defend themselves from the enemy, but at certain doses can be used as medicine. Phytochemical analysis results of C. fragrans Vent Willd leaf extract are presented in Table 1.

Table 1. Results of phytochemical analysis of C. fragrans Vent Willd leaf extract.

\begin{tabular}{lccc}
\hline $\begin{array}{c}\text { Type of the } \\
\text { secondary } \\
\text { metabolites }\end{array}$ & \multicolumn{2}{c}{ Types of C. fragrans Vent Willd Leaf Extract } \\
Alkaloids & n-Hexane & Ethyl acetate & Ethanol \\
Steroids & + & ++ & ++ \\
Triterpenoid & + & + & - \\
Flavonoids & - & - & + \\
Saponin & + & - & + \\
Tannin & - & + & ++ \\
Quinon & - & + & + \\
Color & - & - & + \\
\hline
\end{tabular}

Note : (+) Present and (-)Absent

The results of phytochemical analysis of secondary metabolites, showed that the n-hexane extract of C. fragrans Vent Willd leaves contained alkaloid, steroid and flavonoid secondary metabolites. There are alkaloids, steroids, saponins and tannins in ethyl acetate extract. In the ethanol extract there are alkaloids, triterpenoids, flavonoids, saponins, tannins and quinones (Table 1).

In ethyl acetate extract and ethanol of C. fragrans Vent Willd leaves there were more alkaloids than n-hexane extract. Flavonoids were only found in n-hexane and ethanol extracts. Steroids are only found in n-hexane and ethyl extracts of C. fragrans Vent Willd leaves. In 
ethyl acetate extract, leaves of C. fragrans Vent Willd contained alkaloids, steroids, saponins and tannins, whereas in ethylacetate extract leaves of Clerodendrum phlomidis L. there are steroids, alkaloids, phenolics, amino acids and no saponins, sugars, flavones and catachins (Devika et al., 2012).

Extract of $\mathrm{n}$-hexane from C. fragrans Vent Willd leaves contained secondary metabolites of alkaloids, steroids and flavonoids, whereas in hexane from C. philippinum (one species of the genus Clerodendrum in India) positively contained alkaloids, carbohydrates, flavonoids, essential oils and fats. (Udayanet al. 2014).

Ethanol extract of C. fragrans Vent Willd leaves contained the most complete secondary metabolites compared to n-hexane and ethyl acetate extracts, namely alkaloids, triterpenoids, flavonoids, saponins, tannins and quinones, except steroids, while Udayan et al. (2014) reported that crude ethanol extract from the leaves of Clerodendrum philippinum (one of the species of the genus Clerodendrum in India), contained flavonoids, steroids, glycosides, phenolic compounds, tannins, saponins, carbohydrates, alkaloids and essential oils. Devikaet al. (2012) reported that the ethanol extract of Clerodendrum phlomidis L leaves also contained steroids and phenols.

Saponins are widely found in ethanol extract of leaves of C. fragrans Vent Willd, followed by ethyl acetate extract and there is no saponin in n-hexane extract. Whereas the results of Devikaet al. (2012) study showed that saponins were not present in ethyl acetate, alcohol and chloroform extracts from the leaves of Clerodendrum phlomidis L. Dey et al., 2014 reported on leaf extracts of Clerodendrum viscossum Vent containing alkaloids (1.30 \pm $0.09 \mathrm{~g} / 100 \mathrm{~g})$, flavonoids $(16.04 \pm 1.33 \mathrm{mg} / \mathrm{g})$, phenolic compounds $(57.48 \pm 0.71 \mathrm{mg} / \mathrm{g})$, tannins $(46.63 \pm 0.03 \mathrm{mg} / \mathrm{g}) 100 \mathrm{~g})$, and saponins $(13.31 \pm 0.47 \mathrm{~g} / 100 \mathrm{~g})$.

The results of Simorangkir et al. (2017a) also showed that the most secondary types of metabolites were ethanol extract (polar) of Solanum blumei Ness ex Blume leaves compared to n-hexane (semi-polar) and ethanol (polar) extracts, namely alkaloids, steroids, triterpenoids, flavonoids, phenols, saponins ,tannin and quinone. Sujatha et al. (2013), reported that the nonpolar fraction of Brassica nigra (Koch) plant is stronger that antimicrobial activities than crude extract (polar). Sowmya et al. (2013) also stated the same thing that the most common types of secondary metabolites were in ethanol extract compared to ethyl acetate, chloroform, petroleum ether and water extracts from Boerhaavia diffusa Linn (root), Terminalabellerica Linn (fruit) and Tribulusterestris Linn (fruit) plants. Flavonoids and triterpene are present in all plant extracts.

Phytochemicals are the core of phytomedicin. The therapeutic efficiency of phytomedicines directly correlates with the presence of various phytochemicals. Some research results show that alkaloid, flavonoid, steroid, tannin, saponin secondary phenol, which are found in plants, have various biological activities/ drugs.

Flavonoids are one of the major classes of phytochemicals associated with diverse pharmacological activities which include antioxidant, anti-cancer and anti-aging properties (Sharma, 2006). Flavonoids with two 6-carbon rings and one 3-carbon linkage (usually forming a 3 ring) are divided into chalcones, flavones, flavonols, flavanones, isoflavones, flavan-3-ols, and anthocyanins, according to the modification of the basic carbon skeleton. Suggest that flavonoids may bind to gamma-aminobutyric acid. A receptors having sedative or anxiolytic effects on the nervous system and can act to upregulate the cholinergic nervous system (Kennedy et al., 2011) and flavonoid-rich supplements may reduce neuro degenerative processes (Spencer, 2010).

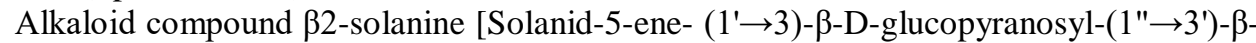
D galactopyranoside] with the molecular formula $\mathrm{C}_{39} \mathrm{H}_{63} \mathrm{NO}_{11}$ found in ethanol extract of $S$. 
Blumei Nees ex Blume fruit (Simorangkir et al., 2016). That ethanol extract of S. Blumei Nees ex Blume fruit has the activity of inhibiting the growth of L1210 leukemia cancer cells with $\mathrm{IC}_{50}$ values of $14,88 \mathrm{mg} / \mathrm{mL}$ (Simorangkir et al., 2017b).

Saponins also exhibit a wide range of biological activity such as immunostimulatory, anti-inflammatory, hypocholesterolemic activity etc(Tamura et al., 2012).

Various plant derived phenolic compounds such as curcumin, genistein, resveratrol and catechins act as potent inhibitors of growth factor and signalling pathways associated with cancer (Wahle et al., 2010; Shen et al., 2003). Plant derived phenolics have also demonstrated immunomodulatory activity by modulating cytokines and chemokines.

Several different plants of the Clerodendrum genus have been extensively studied in the practice of different traditional medicines. Based on the results of research on plant secondary metabolites that have been carried out, local plants of sarang banua (Clerodendrum fragrans Vent Willd) have the esential to be developed as natural materials that have various biological activities/drugs.

\section{Conclusions}

Through the maceration process of the sarang banua (Clerodendrum fragrans Vent Willd) leaf by using its polarity multilevel solvent, the highest yield obtained sequentially was ethanol extract $(15.42 \% \mathrm{w} / \mathrm{w})$, ethyl acetate $(10.63 \% \mathrm{w} / \mathrm{w})$ and $\mathrm{n}$-hexane $(3.82 \% \mathrm{w} / \mathrm{w})$. Secondary metabolites found in ethanol extract are alkaloids, triterpenoids, flavonoids, saponins, tannins and quinones, ethyl acetate extracts have alkaloids, steroids, saponins, tannins and n-hexane extracts have alkaloids, steroids and flavonoids.

Based on the results of research on plant secondary metabolites that have been carried out, further research is needed to test the bioactivity and isolation of active compounds in local plant of C. fragrans vent Willd as raw material for natural medicine Indonesian.

\section{Acknowledgements}

Acknowledgments are addressed to the Directorate of Research and Community Service, Directorate General of Research and Development Strengthening, Ministry of Research Technology and Higher Education, for the provision of research funds in accordance with the Research Contract Number 027 / UN33.8 / LL / 2018 dated February 12, 2018.

\section{References}

[1] Devika, R., Justin, K., Phytochemical and in vitro micropropogation studies of Clerodendrum phlomidis L. Jornal of Pharmacy Research, 5 (8), 4396-4398, 2012.

[2] Dey, P., Dutta, S., Chaudhuri, T.K., Phytochemical analysis of the leaves of Clerodendrum viscossum Vent. International Journal of Pharmacy and Pharmaceutical Sciences, 6 (12), 254-258, 2014.

[3] Harborne, J. B., Phytochemical methods : A guide to modern techniques of plant analysis, Chapman and Hall, London, 1998.

[4] Kar, P., Goyal, A.K., Das, A.P and Sen, A., Antioxidant and Pharmaceutical Potential of Clerodendrum L :An Overview, International Journal of Green Pharmacy, 210-216, 2014. 
[5] Kennedy, D. O., Wihgtman, e. L., Herbal extracts and phytochemicals : plant secondary metabolites and the enhancement oh human brain function. Advances in Nutrition, 2, 32-50, 2011 [6] Senjobi, C.T., Fasola, T.R danAziba, P.L., Phytochemical and Analgesic Evaluation of Methanol Leaf Extract of Clerodendrum volubile Linn, Ife Journal of Science, 19(1), 141-145, 2017. [7] Sharma, D.K., Pharmacological properties of flavonoids from plants.Journal of Scientific and Industrial Research, 65, 477-484, 2006.

[8] Shen, F., Chen, S.J., Dong, X.J., Zhong, H., Li, Y.T., Cheng, G.F., Suppresion of IL-8 gene transcription by resvoratrol in phorbol ester treated human mococyte cells. Journal of Asian Natural Products Research, 5, 151-157, 2003.

[9] Shrivastava, N., Patel, Clerodendrum and Heathcare : An Overview, Medicinal and Aromatic Plant Science and Biotechnology, Global Sciences Book, Gujarat, India, pp. 1-9. : An Overwiew, 2007.

[10] Simorangkir, M., Barus, T., Surbakti, R. \& Simanjuntak, P., Isolation and toxicity of steroidal alkaloid glycoside from fruits of ranti hitam (Solanum blumei Nees ex Blume). Asian journal of chemistry, 28(1), 203-206, 2016.

[11] Simorangkir, M., Surbakti, R., Barus,T. \& Simanjuntak, P., Secondary metabolites phytochemical analysis of leaves and fruit extract Solanum blumei Nees ex Blume local. J. Pend Kimia (JPKim), 9 (1), 244-248, 2017.

[12] Simorangkir, M., Silaban, S., Surbakti, R., Barus,T., Simanjuntak,P., Aktivitas anti kanker ekstrak etanol buah ranti hitam (Solanum blumei Nees ex Blume).Chimica et Natura Acta, 5 (1), 31$35,2017$.

[13] Smallwood, I.M., Handbook of organik solvent properties. John Wiley \& Sons Inc, New York, Toronto, 1996.

[14] Sowmya, S., Lakshmidevi, N., Qualitative phytochemical analysis of nonpolar to polar solvent extracts of selected medicine plants. International Journal of Current Research, 5 (12), 3618-1621, 2013.

[15] Spencer, J., The impact of fruit flavonoids on memory and cognition.British Journal of Nutrition, (104), 40-47, 2010.

[16] Sujatha, S., Suresh, A., Polar and non polar solvent extraction and pharmacological evaluation of four different parts from Brassica nigra (Koch) plant. Journal of Pharmaceutical and Scientific Innovation (JPSI), 2 (3), 27-29, 2013.

[17] Tamura, Y.M., Masazumi, Yamamoto, M., Application of saponin-containing plants in food and cosmetics.In, Sakagama H, editor.Alternatif Medicine. In Tech, 2012.

[18] Udayan, D., Nair, S.N., Padinchareveetil, S.K., Palayullaparambil, A.K.T., Juliet, S., Ravindran, R and Pradeep, A.K., Evaluation of Phytochemical Constituents, Proximate and Flourescence Analysis of Ethanolic Extract and Fractions of Clerodendrum philippinum schauer Found in Wayanad Region of Kerala, India,Research Journal of Chemical Sciences, 4(9), 1-6, 2014. [19] Wahle, R. W.J., Brown, I. Rotondo, D., Heys, S.D., Plant phenolics in the prevention and treatment of cancer.Advances in Experimental Medicine and Biology, 698, 36-51, 2010. 